\title{
FRP-confined concrete filled PVC tubes: a new design concept for ductile column construction in seismic regions
}

\section{Mostafa Fakharifar, Ph.D.}

Post-Doctoral Fellow, Department of Civil, Architectural and Environmental Engineering, Missouri University of Science and Technology, 209 Pine Building, 1304 N. Pine Street, Rolla, MO 65409

Phone: 573-341-6845, Fax: 573-341-4497

Email: mfhdc@mst.edu

\section{Genda Chen, Ph.D., P.E. (Corresponding author)}

Professor, Department of Civil, Architectural and Environmental Engineering, Missouri University of Science and Technology, 328 Butler Carlton Hall, 1401 N. Pine Street, Rolla, MO 65409

Phone: 573-341-4462, Fax: 573-341-4729

Email: gchen@mst.edu 


\begin{abstract}
:
In their recent work [1], authors have introduced and validated a new ductile design concept of confined concrete-filled polyvinyl-chloride tubular (CCFPT) columns through experimental and analytical studies. Confinement was provided with the use of a polyvinylchloride (PVC) tube and fiber-reinforced polymer (FRP) wrappings or FRP with a sandwiched layer of foam to enhance impact energy reduction due to potential FRP rupture and PVC fracture. In the present paper, additional flexural tests on CCFPT columns were undertaken to further investigate the structural behavior of the proposed system for column construction in seismic regions. Axial and flexural behavior of CCFPT columns was investigated with compressive and flexural tests, respectively, and compared with those of their corresponding concrete-filled polyvinyl-chloride tubular (CFPT) and FRP-wrapped (FW) columns. Test results obtained from $152 \times 305 \mathrm{~mm}(6 \times 12$ in. $)$ stub columns under axial loads and $152 \times 1524 \mathrm{~mm}(6 \times 60$ in.) flexural beams under four-point loads indicated that the CCFPT columns can significantly enhance strength over the CFPT columns and enhance ductility over the FW columns. The transverse confining pressure from FRP wrapping and the interface property between the FRP and PVC proved critical in CCFPT design. Furthermore, the idea of introducing a cushioning foam layer between FRP layers and PVC to lessen the brittleness of FRP rupture in seismic regions proved effective.
\end{abstract}

\title{
Key Words:
}

Confined concrete; Seismic; Ductility; Column construction; Strength; FRP Composites. 


\section{Introduction}

Past studies have demonstrated the enhanced structural performance of concrete-filled tube (CFT) systems, incorporating steel or FRP confining tubes, as an improved form of gravitational and lateral load resisting system for tall buildings/bridge columns and pile-footings $[2,3]$. Concrete-filled steel tube (CFST) and concrete-filled FRP tube (CFFT) column systems are the two most common types of CFTs that have been investigated at both member and system level ([3-15]). CFT system demonstrate remarkable properties in terms of enhanced structural performance and project economy/constructability [3, 8-12, 16-27]. Some studies (e.g., [2, 17, 28, 29]) have incorporated the additional confinement provided by FRP wraps in the CFST system, in which the CFST is confined by FRP jacket.

Durability of reinforced concrete (RC) structures and steel-concrete composite structures under severe environmental conditions has always been a major concern [30]. It is estimated only in the U.S. over $\$ 1$ billion is spent annually for repair and replacement of waterfront piling systems [31]. Considering the corrosion of steel tubes [3, 31], durability, and potential long-term bond issues, in addition to brittle failure of FRP materials [32], few research studies investigated other types of confining-tubes. Commercially-available thermoplastic pipes, like high-densitypolyethylene (HDPE) and polyvinyl-chloride (PVC) pipes for improved durability of RC structures have been investigated (e.g. [30, 33-35]). Experimental studies on CFPTs have been limited to axial compression tests only [19]. PVC materials, exhibiting remarkable mechanical properties compared to other general purpose olefin plastics, demonstrate impressive ratio of cost to performance, specifically remarkable durability [33-35]. Investigation of soil-buried PVC pipes dug up after 60 years of active use, indicated no deterioration and likely to have a further life expectancy of 50 years [36]. Thermal conductivity of PVC is only $0.45 \sim 0.6 \%$ of a steel tube, 
which provides a stable curing condition for the core concrete to achieve high performance and high durability [35]. Study by Gupta and Verma [37] on RC-filled-PVC tubes subjected to harsh environmental condition indicated that no degradation in the strength and ductility of reinforced concrete-filled PVC specimens was observed. Test results on RC-filled-PVC tubes submerged in saturated sea water for 6 months revealed that the microstructure and chemical composition of the PVC jacket remained nearly identical after exposure to sea water [37]. The improved durability of PVC material allows potential applications of this system for wide variety of structural systems exposed to harsh environmental conditions (marine and saline environments).

Aging of the polymer, could affect the behavior of the FRP pipes/tubes and PVC pipes differently [30, 35]. Study by Li et al. [38] indicated that environmental conditioning - in a tank with boiled water and UV light for seven days only - resulted in 57-76\% loss of strengthening efficacy, and 43-48\% stiffness degradation of FRP after conditioning. Study by Jakubowicz et al. [39] on accelerated and natural aging of PVC materials, indicated that aging in air at $80^{\circ} \mathrm{C}$ and $90{ }^{\circ} \mathrm{C}$ for up to eight weeks caused no significant changes in mechanical properties and elongation at fracture of PVC material. PVC has outstanding anti-corrosion characteristics, and FRP jackets could be applied as additional confinement to compensate for the relatively weak confining properties of PVC pipes, introducing the confined concrete-filled PVC tube (CCFPT), with exceptional durability and mechanical strength.

Against this background, this study is aimed at investigating the structural performance of the CCFPT technology. This composite column consists of an exterior FRP-PVC shell confining the core concrete. This system is lightweight, cost-effective, and features the enhanced strength capacity of FRP materials, in addition to the superior corrosion resistance of PVC, 
which allows a feasible proposal for its application in pile foundation, bridge columns, and harsh environment (acid-based and sea water).

Test results on axial compressive and flexural behavior of CFPT (PVC confined) and CCFPT (FRP+PVC confined) specimens are reported. It should be noted, herein results of the axial compressive test specimens are included and further explained from the recent authors' study [1], followed by new series of additional flexural tests specifically undertaken for the present paper. Companion FRP-wrapped (FW) specimens were also tested to provide a reliable performance comparison between the extensively studied area of FRP-confined-concrete versus the lesser understood areas of PVC-confined and FRP+PVC-confined concrete. Monotonic axial compressive tests [1] on stub column specimens $(152 \times 305 \mathrm{~mm}(6 \times 12$ in. $))$, in addition to simplysupported beam $(152 \times 1524 \mathrm{~mm}(6 \times 60$ in. $))$ tests, on CFPT, CCFPT and FW were undertaken. As illustrated in Figure 1, CCFPT is a combination of FW and CFPT configurations. Companion FW and CFPT have been tested, to appropriately identify the potential advantages/disparities of the CCFPT system, versus FW and CFPT systems when utilized individually.

\section{Experimental program}

\subsection{Axial and flexural test specimens}

Axial and flexural behavior of FRP-wrapped (FW), concrete-filled-PVC tube (CFPT), and confined-concrete-filled-PVC tube (CCFPT) specimens has been investigated in this study. A total of twenty one $152 \times 305 \mathrm{~mm}(6 \times 12$ in. $)$ stub cylindrical columns - referred as stub specimens hereafter - were tested under monotonically increasing compression to investigate the confinement effect of the FRP, PVC or FRP+PVC jacket on axially loaded normal strength concrete (NSC). As noted earlier, results of these test specimens are adopted from the part of the 
recent authors' study [1] and are presented as these results are relevant for investigating the companion flexural specimens tested here. Seven $152 \times 1524 \mathrm{~mm}(6 \times 60$ in.) cylindrical specimens - referred as beam specimens hereafter - were tested under transverse four-point bending to investigate the flexural capacity of the FW, CFPT and CCFPT systems. Selfconsolidating concrete (SCC) mix was used to cast the beam specimens. This would replicate using SCC mix for casting deep-concrete-pile-foundations to alleviate air cavities and soil pockets in field applications. All of the specimens included plain NSC without internal reinforcement.

All the CFPT, CCFPT, and FW specimens were manually manufactured. For CFPTs, the PVC pipe was cut to the required length $(305 \mathrm{~mm}$ (12 in.) and $1524 \mathrm{~mm}$ (60 in.) for stubs and beams, respectively), followed by affixing a wood board at the bottom of the tube, which functioned as a stay-in-place formwork during concrete casting. For FW and CCFPT specimens, FRP sheets were applied using a manual wet-layup process, which required wrapping epoxyresin-impregnated fibers around precast-concrete cylinders (for FWs) or PVC (for CCFPTs). For all the FW and CCFPT stub specimens, the FRP wraps were applied in the hoop direction only. All the FRP materials used in this study were unidirectional fibers, and multiple layers in different orientations have been used for beam specimens' preparation. To avoid direct axial stress transfer from the steel loading platens onto the FRP, the FRP jackets were recessed by 5 mm (0.2 in.) at both ends. For FW and CCFPT beam specimens, details on fibers orientation are reported later in the paper.

The stub column test matrix as shown in Table 1 included six FWs, five CFPTs, and ten CCFPTs. Table 1 also includes the designation of specimens for later reference. The bearing effect of PVC on the axial load carrying capacity of column specimens was investigated by 
recessing the PVC tube from both ends as illustrated in Figure 1(d). The two specimens with gap at each end were designated as CFPT-G40-w gap\#1 and 2. Additional CCFPTs (CCFPT-G401G-foam\#1, 2, 3 and 4 specimens) were included in the stub test matrix, in which presence (or absence) of a cushioning soft layer between the PVC tube and FRP wrap was evaluated (Figure 1(e)). This cushion was basically a soft and compressible foam layer to: (1) delay the engagement of the FRP wrap and thus obtain larger axial deformation prior to rupture of the FRP jacket, (2) inhibit the PVC tube from immediate and/or simultaneous fracture after the FRP rupture, and (3) control the unnecessary strength enhancement. This system was tested to examine its efficacy for regions of high seismicity to avoid the undesirable brittle failure of FRP at ultimate limit state. The foam layer introduced in this study was used to absorb and/or lessen the impact energy released upon FRP rupture. The foam between the PVC tube and FRP wrap may reduce the impact susceptibility of CCFPT columns under external impact loading [40], which is beyond the scope of current study.

The flexural beam test matrix as shown in Table 2 included two FWs, one CFPT, and four CCFPTs. Table 2 also details the orientation and number of FRP plies, stacking sequence of FRP plies, and presence (or absence) of foam layer between the PVC tube and FRP wrap in CCFPT columns or between the FRP layers in FW columns. For FW-1, two plies of longitudinal FRP were applied directly on a precast-concrete beam and then confined by 3-plies of FRP in hoop direction. FW-2 was the same as FW-1 except that a foam layer was introduced after installation of the first longitudinal FRP and reinforced by a second longitudinal FRP layer before 3-plies of hoop fibers were installed. CFPT-1 represented a PVC tube filled with concrete. CCFPT-1 included 3-plies of FRP wrapped around the CFPT-1 in hoop direction. In CCFPT-2, foam was applied on the PVC tube before the 3-plies of hoop fibers were applied. CCFPT-3 included 2-plies of longitudinal FRP applied on the PVC tube and wrapped by 3-plies of FRP in 
hoop direction. CCFPT-4 is the same as CCFPT-3 except a foam layer was applied on the PVC tube before 2-plies of longitudinal and 3-plies of hoop fibers were installed.

\subsection{Material properties}

\subsubsection{Concrete}

Two different NSC mixes with a target unconfined compressive strength $\left(f^{\prime}{ }_{c o}\right)$ of $50 \mathrm{MPa}$ (7.0 ksi); and $25 \mathrm{MPa}(3.6 \mathrm{ksi})$ at 28 days were used in the manufacture of stub column and flexural beam specimens, respectively. Plain concrete cylinders with $152 \times 305$ mm (6×12 in.) dimensions were tested at selected time intervals to determine the in-place unconfined concrete strength. The measured average compressive strength of stub and beam specimens during the period of testing was 49.5 (7.0) and $24.12(3.5) \mathrm{MPa}(\mathrm{ksi})$, respectively.

\subsubsection{FRP}

Two types of glass FRP (GFRP) were used to fabricate stub column and beam specimens, since during the beam specimens preparation the same FRP used for stub specimens was not available to purchase. Properties of GFRPs used in the manufacture of specimens were obtained from flat coupon tests (as per ASTM D3039 [41]). GFRP used to manufacture stub specimens had the following properties: tensile strength $\left(f_{f r p}\right)=1,228 \mathrm{MPa}(178 \mathrm{ksi})$, elastic modulus $\left(E_{f r p}\right)=$ $79.18 \mathrm{GPa}(11,484 \mathrm{ksi})$, and ultimate tensile strain $\left(\varepsilon_{f r p}\right)=1.55 \%$, with a nominal thickness of $\left(t_{f}\right)=0.373 \mathrm{~mm} / \mathrm{ply}(0.015 \mathrm{in} . / \mathrm{ply})$. GFRP used for beam specimens had the following properties: $f_{f r p}=431 \mathrm{MPa}(62.5 \mathrm{ksi}), E_{f r p}=27.2 \mathrm{GPa}(3,945 \mathrm{ksi}), \varepsilon_{f r p}=1.59 \%$, and $t_{f}=1.3 \mathrm{~mm} / \mathrm{ply}(0.05$ in./ply). For the FW and CCFPT specimens, a thin layer of epoxy resin was applied to the concrete or PVC tube surface prior to manually wrapping the epoxy-impregnated FRP. Specimens with 1 and 3 layers of FRP were wrapped with 1 continuous sheet with 1 overlap 
zone. To prevent premature debonding failure, the FRP sheets were wrapped around the PVC or precast concrete cylinders continuously, with an additional overlap length of $152 \mathrm{~mm}(6 \mathrm{in}$.$) and$ $144 \mathrm{~mm}$ (5.7 in.) for CCFPT and FW specimens, respectively, corresponding to $30 \%$ of the specimen's circumference.

\subsubsection{PVC}

Commercially available Grey schedule 40 PVC pipe (as per ASTM D1785 [42]) used for water supply with nominal pressure of $1.24 \mathrm{MPa}(180 \mathrm{psi})$ was used to manufacture the stub and beam CFPTs and CCFPTs. The selected PVC pipe had grey color, with an inside diameter of 152 mm (6 in.) with a minimum wall thickness of $7.10 \mathrm{~mm}(0.28 \mathrm{in}$.), as shown in Figure 1 . All the CFPT, CCFPT, and FW specimens had a concrete infill of $152 \mathrm{~mm}$ (6 in.) in diameter, measured at the concrete core. Mechanical properties of the PVC pipe was specified by testing a minimum of five tensile dogbone coupon specimens, as illustrated in Figure 2(a) (as per ASTM D638 [43]). The PVC coupons exhibited significantly ductile behavior reaching to an average fracture strain of $46 \%$. The tensile coupon PVC specimens had the following properties: ultimate tensile strength at yield $\left(f_{y, p v c}\right)=50.36 \mathrm{MPa}(7.3 \mathrm{ksi})$, modulus of elasticity $\left(E_{p v c}\right)=4.03 \mathrm{GPa}(585 \mathrm{ksi})$, ultimate fracture strain $\left(\varepsilon_{u, p v c}\right)=46 \%$, and Poisson's ratio $(v)=0.419$. Besides, two similar hollow PVC tubes having the same height as the stub specimens were tested under axial compression. The axial stress-strain relationships are illustrated in Figure 2(b), and the following properties were obtained under axial compression: peak axial load sustained= $208.5 \mathrm{kN}$ (46.9 kips), yield stress $=41.3 \mathrm{MPa}(6 \mathrm{ksi})$, peak stress $=50.93 \mathrm{MPa}(7.4 \mathrm{ksi})$, and axial strain at peak $=4.27 \%$. 


\subsection{Instrumentation and testing procedure}

\subsubsection{Stub specimens under compression}

The specimens were tested under a constant displacement control regimen at approximately $0.50 \mathrm{~mm}$ (0.02 in.) per minute. For the CFPT and CCFPT specimens, the load was applied to the entire specimens' cross section. The in-place strengths of the unconfined concrete $\left(f^{\prime}{ }_{c o}\right)$ were measured at the time of testing, and the corresponding axial strain $\left(\varepsilon_{c o}\right)$ was calculated according to the expression given by Tasdemir et al. [44] as shown below.

$$
\varepsilon_{c o}=\left(-0.067 f_{c o}^{\prime}+29.9 f_{c o}^{\prime}+1053\right) \times 10^{-6}
$$

where $f^{\prime}{ }_{c o}$ is in MPa.

For each specimen, three vertical linear variable differential transformers (LVDTs) were utilized to measure the axial deformations, which were placed equidistantly at 120-degree increments between the top and bottom supporting steel plates, as shown in Figure 3(a). In addition, three horizontal LVDTs located at the specimens' mid-height were used to capture the lateral dilation (radial expansion) of the specimens. Moreover, specimens were instrumented at the mid-height with three strain gages to measure axial strains. Hoop strains were measured by three strain gages that were spaced equidistantly around the perimeter at the specimen's midheight outside the overlap region. For FW and CCFPT specimens, one additional hoop strain gage was installed on the overlap region of the FRP wrap.

The stub specimens under axial compressive loading were identified according to the confinement material, where the FRP type, number of FRP layers, and PVC type are specified. Confinement tube is designated as either FW, CFPT, or CCFPT. The symbol $\mathrm{G}$ is used to represent the type of FRP, namely: glass $(\mathrm{G})$ preceded by the number of layers. For CFPT and CCFPT specimens the letter G was used in specimens designation to specify the PVC pipe 
schedule/color followed by a number that determines the PVC pipe schedule. As stated earlier, the gray Schedule 40 PVC pipe was used in this study, hence the G40 designation was used accordingly. A final number was provided to identify between nominally identical specimens. Details on all the stub specimens are presented in Table 1. For example, a FRP-wrapped specimen confined with one layer of GFRP, which is the first in its group would be FW-1G\#1. A CFPT specimen encased by the gray Schedule 40 PVC tube, and is third in its group would be labelled as CFPT-G40\#3. Lastly, a CCFPT specimen encased by the gray Schedule 40 PVC tube and one layer of GFRP, and is the first in its group would be CCFPT-G40-1G\#1.

Two companion CFPT specimens with 12-mm gap at both ends (CFPT-G40-w gap\#1 and 2) were tested (Figure 1(d)). Stub specimens with foam layer between the PVC tube and FRP wrap (CCFPT-G40-1G-foam\#1, 2, 3 and 4 specimens) were also included (Figure 1(e)). For CCFPT-G40-1G-foam\#1 and 2 a $4.175-\mathrm{mm}$ (0.16 in.) foam was utilized, wherein for the CCFPT-G40-1G-foam\#3 and 4 a 1-mm (0.04 in.) foam layer was used.

\subsubsection{Beam specimens under transverse bending}

The $1.321 \mathrm{~m}$ (52 in.) long beams (clear span-length) were tested as simply supported, using a four-point bending setup as shown in Figure 3(b). The beam specimens were instrumented with linear position transducers (LPTs) at mid-span, and at quarter points, to record the vertical displacements along the beam. Strain gages in the hoop and longitudinal directions at mid-span were installed on the top and bottom surfaces. Additionally, a strain rosette was installed at mid-distance between the loading points and supports. The load was transferred from the actuator to the test beam through a transfer loading beam at two locations spaced $0.508 \mathrm{~m}(20$ in.) apart. The load was applied monotonically in displacement control (5 mm (0.2 in.) per minute). 


\section{Results and discussion}

\subsection{Stub specimens failure modes}

The typical failure modes of all stub column specimens reported in Table 1 are illustrated in Figure 4. All the FW and CCFPT specimens exhibited brittle rupture of the FRP wrap, which was either a continuous rupture along the specimen's height (Figure 4(c, i)), or localized FRP rupture at the mid-height (Figure 4(a, b)). FWs and CCFPTs failed by rupture of the FRP wrap, immediately followed by failure of the core concrete due to loss of confinement. Catastrophic failure was observed for these two types of specimens. Figure 4(d) exemplifies the extensive concrete damage and fracture of the PVC tube after removing the FRP. Unlike FWs and CCFPTs, the CFPTs exhibited a very ductile behavior with gradual post-peak strength degradation - evident from their recorded stress-strain relationships discussed later in the paperwhere the core concrete continued to crush causing the PVC tube to bulge and sustain very large axial strains. The highly stressed regions on the PVC tube, due to non-uniform dilation of the concrete, correspond to discoloration (white patches due to flow of resin) on the PVC tube (Figure 4(f)). Specifically, two types of failures, namely: shear type and drum type were observed for CFPTs, as shown in Figures 4(g) and 4(h), respectively. Both failures were ductile, and no fracture of the PVC tube was observed. The core concrete was thoroughly crushed and somewhat pulverized, while the PVC tube still retained its integrity. Shear failure of the PVC tube is characterized by damage of the concrete by shear stress developed in one direction due to the relatively weak confining effect of the PVC. The shear crack direction could be interpreted from the appearance of the distorted specimen (Figure 4(g)). In drum type failure, concrete did not crack in one direction, and multiple bulging of the tube was observed (Figure 4(h)). Nonetheless, all the CFPTs exhibited highly ductile behavior. 
CCFPTs with foam demonstrated a ductile behavior similar to their CFPT counterparts, where no distinct FRP rupture could be defined. The FRP rupture was gradual due to slow fracture of the FRP wrap as fibers progressively ruptured that caused tearing and splintering along the specimen's height (Figure 4(i)). In these specimens, the PVC tube remained intact upon FRP rupture, and catastrophic failure was not observed.

\subsection{Stub specimens stress-strain relationship}

The ultimate condition, which consists of the ultimate axial strength $\left(f^{\prime}{ }_{c u}\right)$ recorded at failure of the specimen, corresponding axial strain $\left(\varepsilon_{c u}\right)$ and FRP hoop rupture strain $\left(\varepsilon_{h, \text { rup }}\right)$, of each specimen is reported in Table 1, and the axial stress-strain relationships are presented in Figure 5.

For specimens that their stress-strain relationship consisted of a descending post-peak branch, so that the ultimate stress $\left(f^{\prime}{ }_{c u}\right)$ was lower than the recorded peak stress $\left(f^{\prime}{ }_{c c}\right)$, then both the ultimate stress and the peak stress are reported. For specimens exhibiting a monotonically increasing second branch, the ultimate stress $\left(f^{\prime}{ }_{c u}\right)$ and peak stress $\left(f^{\prime}{ }_{c c}\right)$ were equal, thus only a single value is reported under $f^{\prime}{ }_{c c}$ in Table 1 . For specimens with decreasing second branch, the ultimate conditions $\left(f^{\prime}{ }_{c u}, \varepsilon_{c u}\right.$ and $\left.\varepsilon_{h, \text { rup }}\right)$ presented in Table 1 correspond to $20 \%$ drop below the recorded peak stress.

The ultimate hoop rupture strain $\left(\varepsilon_{h, \text { rup }}\right)$ of each specimen obtained from the average of the lateral strain gages is tabulated in Table 1. Past studies have indicated that the hoop rupture strains obtained from FRP-confined concrete specimens, are usually smaller than the tensile strain of the component fiber advertised by the manufacturers $\left(\varepsilon_{f u}\right)$ (e.g. [45]). The strain reduction factors, $k_{\varepsilon}$, calculated from Eq. (2), were established for FW and CCFPT specimens and are presented in Table 1. 


$$
k_{\varepsilon}=\frac{\varepsilon_{h, r u p}}{\varepsilon_{f u}}
$$

\subsection{Comparison of stress-strain behavior}

The CFPTs exhibited a ductile strain-softening post-peak response without sudden strength loss (Figure 5(c)). Unlike CFPTs, the FWs and CCFPTs when adequately confined (3plies FRP), exhibited a monotonically ascending strain-hardening response up to FRP's rupture (Figures 5(b, g)). For lightly confined FW and CCFPT specimens (1-ply FRP) the strength $\left(f^{\prime}{ }_{c c} / f^{\prime}{ }_{c o}\right)$ and strain $\left(\varepsilon_{c u} / \varepsilon_{c o}\right)$ enhancement ratios were significantly smaller compared to their companion ones with adequate confinement (3-plies FRP), as reported in Table 1.

The CFPTs with gaps at both ends demonstrated very similar behavior to their companion CFPTs up to the peak strength. Nevertheless, upon reaching the peak strength, the unconfined concrete outside the PVC tube started to crush resulting in rapid and unstable postpeak strength degradation (Figure 5(d)). However, the PVC tube in these series of specimens still demonstrated a ductile behavior, similar to CFPTs with full-height tube. Figure 5(i) compares the stress-strain relationships of a CFPT with full-height PVC (CFPT-G40\#1) versus CFPT with gap (CFPT-G40-w gap\#1). The peak strength is very similar for both types of specimens.

The CCFPTs with foam exhibited distinct axial stress-strain relationship due to the cushioning properties of foam. CCFPTs with foam demonstrated similar behavior to CCFPTs without foam up to peak stress, with gradual post-peak strength reduction (Figure 5(f)). Representative stress-strain responses of CCFPTs with foam are compared with a CCFPT without foam (CCFPT-G40-1G\#2) in Figure 5(j). Post-peak strength reduction for CCFPTs with foam was stable, and it was due to the compression of the foam between the PVC and FRP, wherein the FRP wrap was not significantly strained as the foam material was continually compressed. The effect of the foam thickness becomes significant on the second region of the 
stress-strain relationship. For CCFPT-G40-1G-foam\#1 and 2 with the thicker foam, larger strength drop was observed before the FRP wrap starts to provide the confining pressure. In these specimens larger gap is provided by the foam, in which it allows greater dilation of the concrete before the FRP wrap becomes engaged. Presence of the foam layer delayed the onset of FRP rupture as marked on Figure 5(f).

Increasing in the number of FRP layers in the FW and CCFPT specimens lead to increase in ultimate conditions $\left(f_{c u}^{\prime}\right.$ and $\left.\varepsilon_{c u}\right)$, tabulated in Table 1 , and improve the strength $\left(f^{\prime}{ }_{c u} / f^{\prime}{ }_{c o}\right)$ and strain $\left(\varepsilon_{c u} / \varepsilon_{c o}\right)$ enhancement ratios. Figure 5(h) illustrate the influence of confinement pressure $\left(f_{l u}\right)$ provided by different number of FRP layers on the axial stress-strain relationships of FWs and CCFPTs. The nominal confinement ratio $\left(f_{l u} / f^{\prime}{ }_{c o}\right)$ is the ratio of lateral confinement pressure by the confining jacket to the in-place unconfined concrete strength, calculated by the following equation:

$$
\frac{f_{l u}}{f_{c o}^{\prime}}=\frac{2 t_{f} f_{f u}}{D f_{c o}^{\prime}}=\frac{2 t_{f} E_{f} \varepsilon_{f u}}{D f_{c o}^{\prime}}
$$

where $t_{f}=$ total nominal thickness; $E_{f}=$ the modulus of elasticity; $\varepsilon_{f u}=$ ultimate tensile strain of the fibers; and $D=$ the diameter of the confined concrete. As stated earlier, FRP hoop-rupture strain $\left(\varepsilon_{h, \text { rup }}\right)$ are often lower compared to the ultimate rupture-stain of fibers $\left(\varepsilon_{f u}\right)$ obtained from flat-coupon tests and/or reported by manufacturers [46, 47]. The contributory factors for the reduced FRP hoop-rupture strain have been indicated due to curvature of wrapped FRP materials versus flat coupons, as well as the localized stress concentrations on FRP wraps upon concrete cracking [47]. Therefore, the actual confinement ratio $\left(f_{l u, a} / f_{c o}^{\prime}\right)$ was also calculated and presented in Table 1, by the following equation:

$$
\frac{f_{l u, a}}{f_{c o}^{\prime}}=\frac{2 t_{f} f_{f u} k_{\varepsilon}}{D f_{c o}^{\prime}}=\frac{2 t_{f} E_{f}\left(\varepsilon_{f u} k_{\varepsilon}\right)}{D f_{c o}^{\prime}}=\frac{2 t_{f} E_{f} \varepsilon_{h, r u p}}{D f_{c o}^{\prime}}
$$


The actual confinement ratio for FW and CCFPTs with 1-ply and 3-plies of FRP are equal to 0.11 and 0.37 , respectively. It is clear that the shapes of the axial stress-strain relationship for FWs and CCFPTs with similar level of confining pressure are very close (Figure 5(h)). However, CCFPTs experience greater strength $\left(f^{\prime}{ }_{c u} / f^{\prime}{ }_{c o}\right)$ and strain $\left(\varepsilon_{c u} / \varepsilon_{c o}\right)$ enhancement ratios, compared to their companion FWs with identical number of FRP layers. As presented in Table 1, significant gains in strain capacity $\left(\varepsilon_{c u}\right)$ for CCFPTs compared to FWs, irrespective of the number of FRP layers could be observed. Table 1 indicates that CCFPTs consistently exhibited larger strain reduction factors $\left(k_{\varepsilon}\right)$ compared to their $\mathrm{FW}$ companion specimens. Hence, considerably higher strain enhancement ratios were observed for CCFPTs. This could be attributed that in CCFPTs the PVC pipe provides a relatively uniform stress distributing medium, where concrete is maintained and contained integral upon concrete cracking, thus the stress concentrations due to uneven concrete cracking is reduced on the FRP wrap. Additionally, substrate for the FRP wrap in CCFPTs is the PVC tube which compared to concrete surface is very uniform that may enhance the bond between the FRP for the CCFPT.

Comparison of stress-strain relationships and failure modes for the studied specimens clearly indicate that CCFPT specimens demonstrate a higher ultimate stress and strain condition compared to their corresponding FW specimens. This matter directly corresponds to the larger area under the stress-strain curve for CCFPT specimens, which translates into the larger amount of energy stored in CCFPT specimens subjected to axial compression. Therefore, upon FRP rupture in CCFPTs, larger amount of energy is released, thus a more severe sound and damage was observed. Moreover, test results clearly indicated that the CCFPT specimens outperform the corresponding FW specimens in terms of strain reduction factor $\left(k_{\varepsilon}\right)$. Subsequently, according to Eq. 4, it is clear that the nominal FRP wrap (i.e., similar in terms of material and number of 
layers) in the CCFPT is more efficient in confining the core concrete compared to the corresponding FW specimen.

\subsection{Flexural specimens failure modes}

Figure 6 illustrates the condition of core concrete for CFPT, and CCFPT specimens, after removal of the FRP/PVC shell. Depending on the confinement detail and presence of the foam, ductile or brittle failures- evident from their recorded load-mid-span deflection relationships discussed later in the paper- were observed. CFPT-1 experienced uniform flexural cracking distributed along the beam's length (Figure 6(a)). Similarly, presence of the foam between PVC and FRP in CCFPT-2 resulted in uniform distributed flexural cracking (Figure 6(c)). Plastification of PVC tube in CFPT-1 and CCFPT-2 along the constant moment region of the beams was observed. On the contrary, in CCFPT-1, 3, and 4, the damaged region is localized and limited to one or two cross sections only (Figures 6(b), (d) and (e)).

\subsection{Flexural specimens load-displacement relationship}

As shown in Figure 7, either bi-linear or linear-elastic load-deflection relationships were observed. The peak load $\left(P_{\text {peak }}\right)$, recorded mid-span deflection at the peak load $\left(\Delta_{\text {peak }}\right)$, mid span deflection at ultimate $\left(\Delta_{u l t}\right)$ where $20 \%$ drop from the peak load was recorded, and load at ultimate $\left(P_{u l t}\right)$ are reported in Table 2. Peak moment $\left(M_{\text {peak }}\right)$ calculated from the recorded loads are also reported. For specimens exhibiting monotonically increasing behavior, the peak load $\left(P_{\text {peak }}\right)$ and load at ultimate $\left(P_{u l t}\right)$, and similarly the mid-span deflection at peak load $\left(\Delta_{\text {peak }}\right)$ and mid-span deflection at ultimate $\left(\Delta_{u l t}\right)$, were equal, thus only a single value is reported under $P_{\text {peak }}$

and $\Delta_{\text {peak }}$ in Table 2. In Figure 7, the lateral load-mid span displacement relationships with a deflection range from 0 to $180 \mathrm{~mm}$ (7 in.) and from 0 to $80 \mathrm{~mm}(3.1$ in.) are illustrated, 
respectively, so that the post-peak behavior and the onset behavior of the load-displacement curves can be analyzed more clearly.

The CFPT-1 and CCFPT-2 specimens demonstrated ductile bi-linear load-deflection with smooth transition from the linear-elastic to the nonlinear second region. Specimens with FRP in longitudinal direction (FW-1, CCFPT-3 and 4), except FW-2, demonstrated linear elastic behavior with brittle failure.

The effect of the additional confinement for CFPTs through FRP wraps was investigated by comparing CFPT-1 and CCFPT-1. The effect of presence of the foam between the FRP wrap and PVC tube was investigated by comparing the CCFPT-1 and CCFPT-2. CFPT-1 demonstrated the most ductile response compared to all of the beam specimens. However, it demonstrated the smallest flexural strength as shown in Table 2, except for CCFPT-1. While it was anticipated that CCFPT-1 should experience enhanced load carrying capacity compared to CFPT-1 due to the additional confinement provided from 3-plies of hoop FRP, however, upon entering to the nonlinear behavior of CCFPT-1, cracking at the fibers-resin interface resulted in fracture of the PVC tube. A sudden snap sound was heard and the specimen lost its flexural strength, as if the PVC experienced a brittle fracture. Comparison of test results from stub specimens on companion CFPTs versus CCFPTs with FRP wraps demonstrated very promising results. However, contrary to the expected outcome, flexural beam test results indicated the importance of the interface between FRP wrap and PVC tube. Bridge piers and soil-buried-piles are expected to undergo inelastic excursions under lateral forces, experiencing significant flexural deformations. Additional tests are strongly recommended to further understand this new composite system. 
Comparison of CCFPT-2 against CFPT-1 indicates that due to presence of foam, CCFPT2 could demonstrate a ductile behavior with considerable plastic deformations. Similar to CFPT1, the CCFPT-2 demonstrated gradual strength degradation upon reaching its peak-strength. The additional confinement in CCFPT-2 resulted in increase of the initial stiffness and flexural strength. CCFPT-2 developed a peak load of $78.6 \mathrm{kN}$ (17.7 kips) at $79.3 \mathrm{~mm}$ (3.1 in.) mid-span deflection, whereas CFPT-1 was able to sustain a peak load of $67.9 \mathrm{kN}$ (15.3 kips) at $129.6 \mathrm{~mm}$ (5.1 in.) mid-span deflection.

Difference between FWs and CCFPTs was investigated by comparing FW-1 and CCFPT3. For identical fiber architectures, presence of PVC in CCFPT-3 resulted in enhancement of peak strength and initial stiffness (peak load increased from $158.1 \mathrm{kN}$ (35.5 kips) for FW-1 to $169.6 \mathrm{kN}$ (38.1 kips) for CCFPT-3). However, both specimens demonstrated significantly reduced ultimate deflection compared to CFPT-1, with brittle failure.

The concept of introducing foam between longitudinal FRP-plies to lessen the brittleness of the composite system upon rupture of longitudinal FRP was investigated by comparing FW-2 and CCFPT-4. Load-deflection curves with similar trends were observed, with post-peak strength degradation due to longitudinal-FRP rupture. FW-2 demonstrated promising results in terms of inhibiting the brittle failure and exhibiting some level of ductility. In FW-2, upon rupture of the first longitudinal layer of FRP, only a 22\% drop in the load carrying capacity was observed and the specimen recovered to undergo additional deflection and sustained additional load without failure. Contrary to FW-1 with brittle failure, FW-2 demonstrated a two-peak staged-type failure. Presence of foam for CCFPT-4 proved to be less significant, and resulted in three strength drops as marked in Figure 7(b). However, strength loss at peak was significant that resulted in fracture of the PVC. 


\section{Conclusions}

This paper reports the axial and flexural behavior of FRP-confined concrete-filled PVC tubular columns and compares their performance with those of concrete-filled PVC tubular columns and FRP-wrapped columns. Based on the test results and visual observations, the following conclusions can be drawn:

- PVC tube provided low confinement on concrete columns but can undergo significant plastic deformation to cope with concrete dilation. Additional confinement provided by FRP wraps with fibers oriented in hoop direction made the columns sufficiently ductile for potential applications in column design. The FRP wraps can effectively inhibit local buckling of the PVC tube and restrain the lateral dilation of the encased concrete.

- PVC tube contributed little to the axial strength of concrete columns, but FRP wraps with fiber oriented in hoop direction can significantly strengthen the columns.

- PVC tube fractured right after the rupture of its immediate FRP wraps resulting in a sudden loss of load carrying capacity. This brittle failure mode can be prevented by introducing an energy absorption foam layer between the PVC tube and the FRP wraps. In this case, the strength was gradually reduced in steps.

- Introduction of foam between FRP layers proved to be an effective method to lessen the brittleness, and obtainment of relatively ductile member's response upon FRP rupture.

\section{Acknowledgments}

Financial support for this study was provided by the U.S. National Science Foundation under Award No. CMMI-1030399. The views, findings, and conclusions reflected in this paper are those of the authors only and do not necessarily reflect the official views or policies of the sponsor. 


\section{Refrences}

[1] Fakharifar M, Chen G. Compressive behavior of FRP-confined concrete-filled PVC tubular columns. Composite Structures. 2016;141:91-109.

[2] Xiao Y, He W, Choi K-k. Confined concrete-filled tubular columns. Journal of structural engineering. 2005;131(3):488-97.

[3] Fam AZ, Rizkalla SH. Concrete-filled FRP tubes for flexural and axial compression members. Proceedings of ACMBS-3, Ottawa, Canada. 2000:315-22.

[4] Abdelkarim OI, ElGawady MA. Analytical and Finite-Element Modeling of FRP-ConcreteSteel Double-Skin Tubular Columns. Journal of Bridge Engineering. 2014.

[5] Abdelkarim OI, Gheni A, Anumolu S, Wang S, ElGawady M. Hollow-Core FRP-ConcreteSteel Bridge Columns Under Extreme Loading. 2015.

[6] ElGawady MA, Sha'lan A. Seismic behavior of self-centering precast segmental bridge bents. Journal of Bridge Engineering. 2010;16(3):328-39.

[7] Samaan M, Mirmiran A, Shahawy M. Model of concrete confined by fiber composites. Journal of structural engineering. 1998;124(9):1025-31.

[8] Zaghi AE, Saiidi MS, Mirmiran A. Shake table response and analysis of a concrete-filled FRP tube bridge column. Composite Structures. 2012;94(5):1564-74.

[9] Zohrevand P, Mirmiran A. Behavior of ultrahigh-performance concrete confined by fiberreinforced polymers. Journal of Materials in Civil Engineering. 2011;23(12):1727-34.

[10] Louk Fanggi B, Ozbakkaloglu T. Behavior of Hollow and Concrete-Filled FRP-HSC and FRP-HSC-Steel Composite Columns Subjected to Concentric Compression. Advances in Structural Engineering. 2015;18(5):715-38.

[11] Ozbakkaloglu T. Behavior of square and rectangular ultra high-strength concrete-filled FRP tubes under axial compression. Composites Part B: Engineering. 2013;54:97-111.

[12] Ozbakkaloglu T. Compressive behavior of concrete-filled FRP tube columns: Assessment of critical column parameters. Engineering Structures. 2013;51:188-99.

[13] Nisticò N, Pallini F, Rousakis T, Wu Y-F, Karabinis A. Peak strength and ultimate strain prediction for FRP confined square and circular concrete sections. Composites Part B: Engineering. 2014;67:543-54.

[14] Rousakis TC, Kouravelou KB, Karachalios TK. Effects of carbon nanotube enrichment of epoxy resins on hybrid FRP-FR confinement of concrete. Composites Part B: Engineering. 2014;57:210-8.

[15] Rousakis TC, Tourtouras IS. RC columns of square section-Passive and active confinement with composite ropes. Composites Part B: Engineering. 2014;58:573-81.

[16] Dawood HM, ElGawady M. Performance-based seismic design of unbonded precast posttensioned concrete filled GFRP tube piers. Composites Part B: Engineering. 2013;44(1):357-67.

[17] $\mathrm{Hu}$ Y. Behaviour and modelling of FRP-confined hollow and concrete-filled steel tubular columns [Doctoral dissertation]: The Hong Kong Polytechnic University; 2010.

[18] Idris Y, Ozbakkaloglu T. Seismic behavior of high-strength concrete-filled FRP tube columns. Journal of Composites for Construction. 2013;17(6).

[19] Jiang S-F, Ma S-L, Wu Z-Q. Experimental study and theoretical analysis on slender concrete-filled CFRP-PVC tubular columns. Construction and Building Materials. 2014;53:47587. 
[20] Fakharifar M, Chen G, Arezoumandi M, ElGawady M. Hybrid Jacketing for Rapid Repair of Seismically Damaged Reinforced Concrete Columns. Transportation Research Record (TRR): Journal of the Transportation Research Board. 2015;2522:70-8.

[21] Fakharifar M, Chen G, Dalvand A, Shamsabadi A. Collapse Vulnerability and Fragility Analysis of Substandard RC Bridges Rehabilitated with Different Repair Jackets Under Postmainshock Cascading Events. International Journal of Concrete Structures and Materials. 2015;9(3):345-67.

[22] Fakharifar M, Chen G, Lin Z, Woolsey Z. Behavior and strength of passively confined concrete filled tubes. the 10th US national conference on earthquake engineering: July. Anchorage, AK2014.

[23] Fakharifar M, Chen G, Sneed L, Dalvand A. Seismic performance of post-mainshock FRP/steel repaired RC bridge columns subjected to aftershocks. Composites Part B: Engineering. 2015;72:183-98.

[24] Fakharifar M, Chen G, Wu C, Shamsabadi A, ElGawady MA, Dalvand A. Rapid Repair of Earthquake-Damaged RC Columns with Prestressed Steel Jackets. Journal of Bridge Engineering. 2016:04015075.

[25] Fakharifar M, Dalvand A, Sharbatdar M, Chen G, Sneed L. Innovative hybrid reinforcement constituting conventional longitudinal steel and FRP stirrups for improved seismic strength and ductility of RC structures. Front Struct Civ Eng. 2015:1-19.

[26] Fakharifar M, Sharbatdar M, Lin Z, Dalvand A, Sivandi-Pour A, Chen G. Seismic performance and global ductility of RC frames rehabilitated with retrofitted joints by CFRP laminates. Earthquake Engineering and Engineering Vibration. 2014;13(1):59-73.

[27] Naghibdehi MG, Sharbatdar M, Mastali M. Repairing reinforced concrete slabs using composite layers. Materials \& Design. 2014;58:136-44.

[28] Hu H, Seracino R. Analytical model for FRP-and-steel-confined circular concrete columns in compression. Journal of Composites for Construction. 2013;18(3).

[29] Shirmohammadi F, Esmaeily A, Kiaeipour Z. Stress-strain model for circular concrete columns confined by FRP and conventional lateral steel. Engineering Structures. 2015;84:395405.

[30] Wang J-Y, Yang Q-B. Investigation on compressive behaviors of thermoplastic pipe confined concrete. Construction and Building Materials. 2012;35:578-85.

[31] Pando MA, Ealy CD, Filz GM, Lesko J, Hoppe E. A Laboratory and Field Study of Composite Piles for Bridge Substructures. FHWA-HRT-04-0432006.

[32] Karbhari VM. Durability of composites for civil structural applications: Elsevier; 2007.

[33] Kurt CE. Concrete filled structural plastic columns. Journal of the Structural Division. 1978;104(1):55-63.

[34] Toutanji H, Saafi M. Durability studies on concrete columns encased in PVC-FRP composite tubes. Composite structures. 2001;54(1):27-35.

[35] Wang J, Yang Q. Experimental study on Mechanical Properties of concrete confined with plastic Pipe. ACI Materials Journal. 2010;107(2).

[36] Nowack R, Otto OI, Braun EW. „60 Jahre Erfahrungen mit Rohrleitungen aus weichmacherfreiem Polyvinylchlorid (PVC-U). KRV Nachrichten. 1995:1-95.

[37] Gupta PK, Verma VK. Study of concrete-filled unplasticized poly-vinyl chloride tubes in marine environment. Proceedings of the Institution of Mechanical Engineers, Part M: Journal of Engineering for the Maritime Environment. 2014:1475090214560448. 
[38] Li G, Pang S-S, Helms JE, Mukai D, Ibekwe SI, Alaywan W. Stiffness degradation of FRP strengthened RC beams subjected to hygrothermal and aging attacks. Journal of composite materials. 2002;36(7):795-812.

[39] Jakubowicz I, Yarahmadi N, Gevert T. Effects of accelerated and natural ageing on plasticized polyvinyl chloride (PVC). Polymer degradation and stability. 1999;66(3):415-21.

[40] Yan X, Yali S. Impact behaviors of CFT and CFRP confined CFT stub columns. Journal of Composites for Construction. 2012;16(6):662-70.

[41] ASTMD3039/D3039M. Standard test method for tensile properties of fiber resin composites. West Conshohocken (PA): ASTM; 2012.

[42] ASTMD1785. Standard Specification for Poly(Vinyl Chloride) (PVC) Plastic Pipe, Schedules 40, 80, and 120. PVC, Schedule. West Conshohocken: ASTM; 2012. p. 11.

[43] ASTMD638. Standard Test Method for Tensile Properties of Plastics. ASTM International. West Conshohocken (PA)2008.

[44] Tasdemir M, Tasdemir C, Akyüz S, Jefferson A, Lydon F, Barr B. Evaluation of strains at peak stresses in concrete: a three-phase composite model approach. Cement and Concrete Composites. 1998;20(4):301-18.

[45] Vincent T, Ozbakkaloglu T. Influence of fiber orientation and specimen end condition on axial compressive behavior of FRP-confined concrete. Construction and Building materials. 2013;47:814-26.

[46] Chen J, Li S, Bisby L. Factors affecting the ultimate condition of FRP-wrapped concrete columns. Journal of Composites for Construction. 2012;17(1):67-78.

[47] Chen J, Li S, Ai J. Relationship between FRP fracture strains in flat coupon tests, split disk tests and FRP wrapped columns. Proceedings, Second Asian-Pacific Conference on FRP in Structures (APFIS 2009)2009. p. 517-24. 


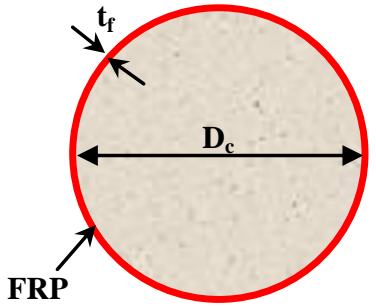

(a) FRP-wrapped (FW)

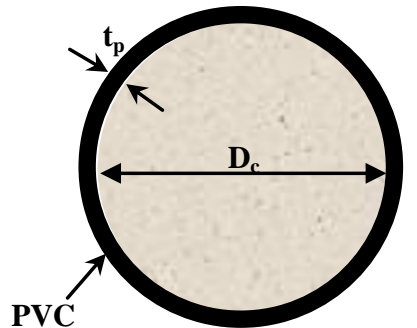

(b) Concrete filled PVC tube (CFPT)

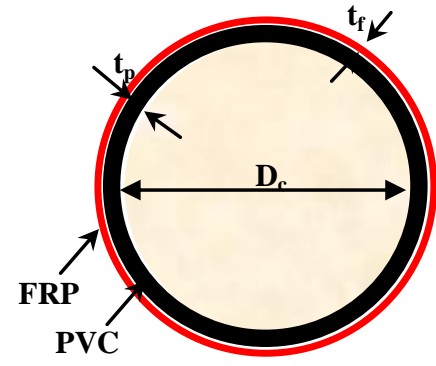

(c) Confined concrete filled PVC tube (CCFPT)

Core concrete diameter, $\mathbf{D}_{\mathbf{c}}: \mathbf{1 5 2} \mathbf{~ m m}\left(\mathbf{6}\right.$ in.); FRP jacket thickness, $\mathbf{t}_{\mathrm{f}}: \mathbf{1}$ or 3 ply; PVC tube thickness: $\mathbf{t}_{\mathrm{p}}: \mathbf{7 . 1 0} \mathbf{~ m m}(\mathbf{0 . 2 8}$ in.)

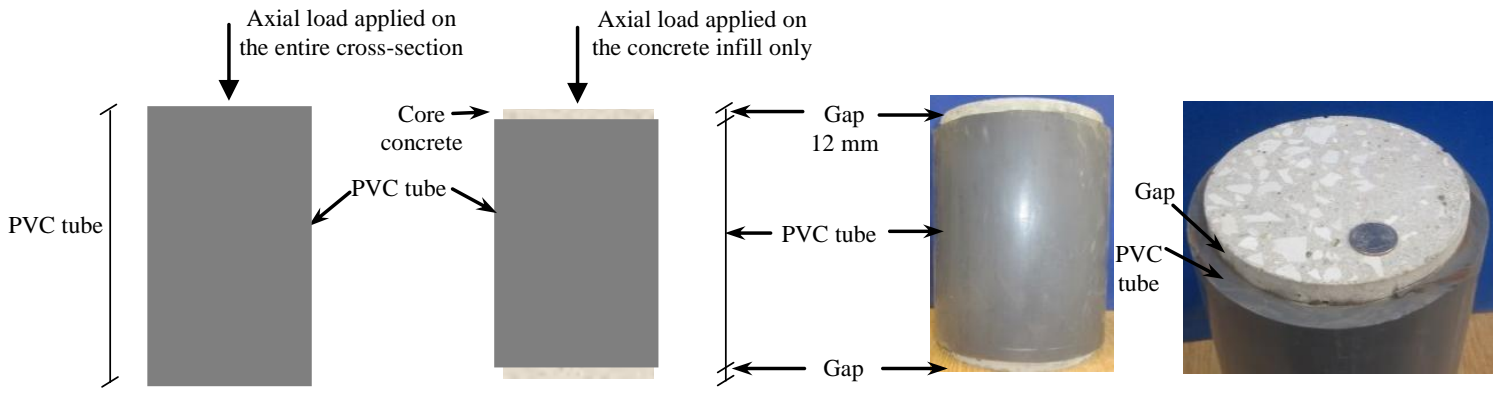

(d) CFPT without and with gaps at both ends (schematic and illustration)
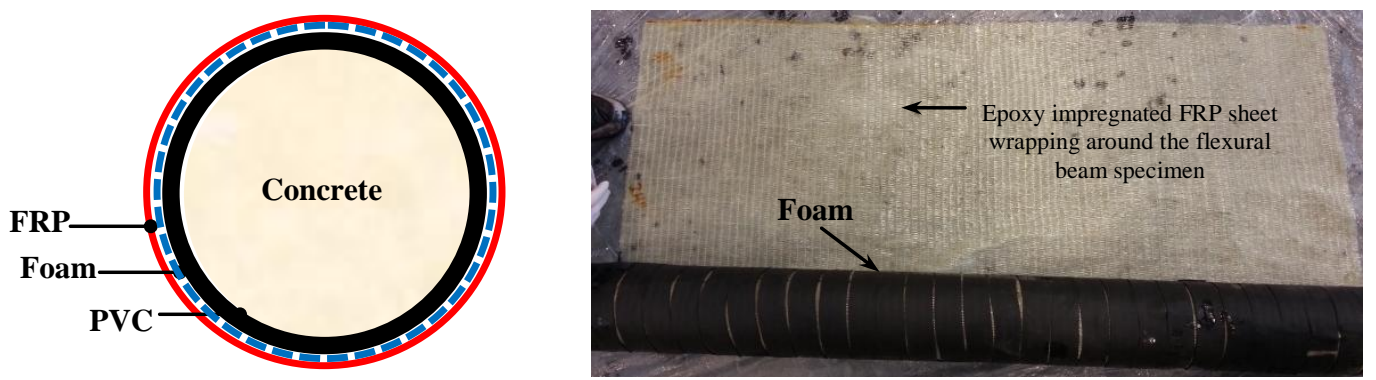

(e) CCFPT with foam layer between PVC tube and FRP warp (schematic and application)

Fig. 1. Details of studied specimens: (a) FRP-wrapped (FW), (b) concrete filled PVC tube (CFPT), (c) confined concrete filled PVC tube (CCFPT), (d) CFPT with and without gaps at both ends, and (e) application of foam layer between PVC tube and FRP wrap. 

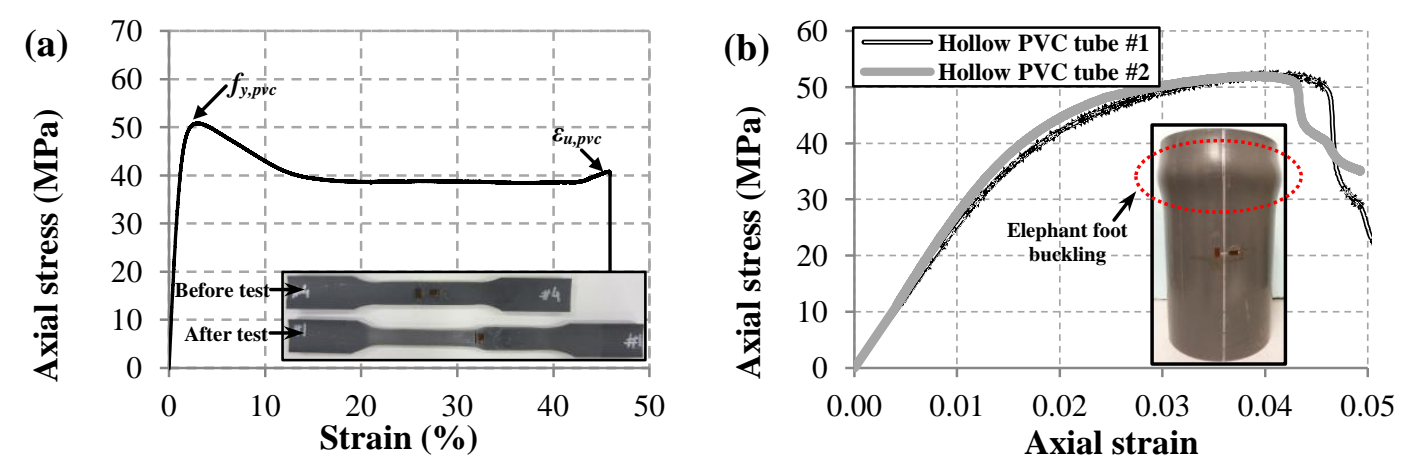

Fig. 2. Measured mechanical properties of PVC pipes: (a) tensile stress-strain curve of PVC pipe coupon up to fracture, and (b) compressive behavior of empty PVC tubes.

Conversion: $1 \mathrm{MPa}=145 \mathrm{psi}$ 

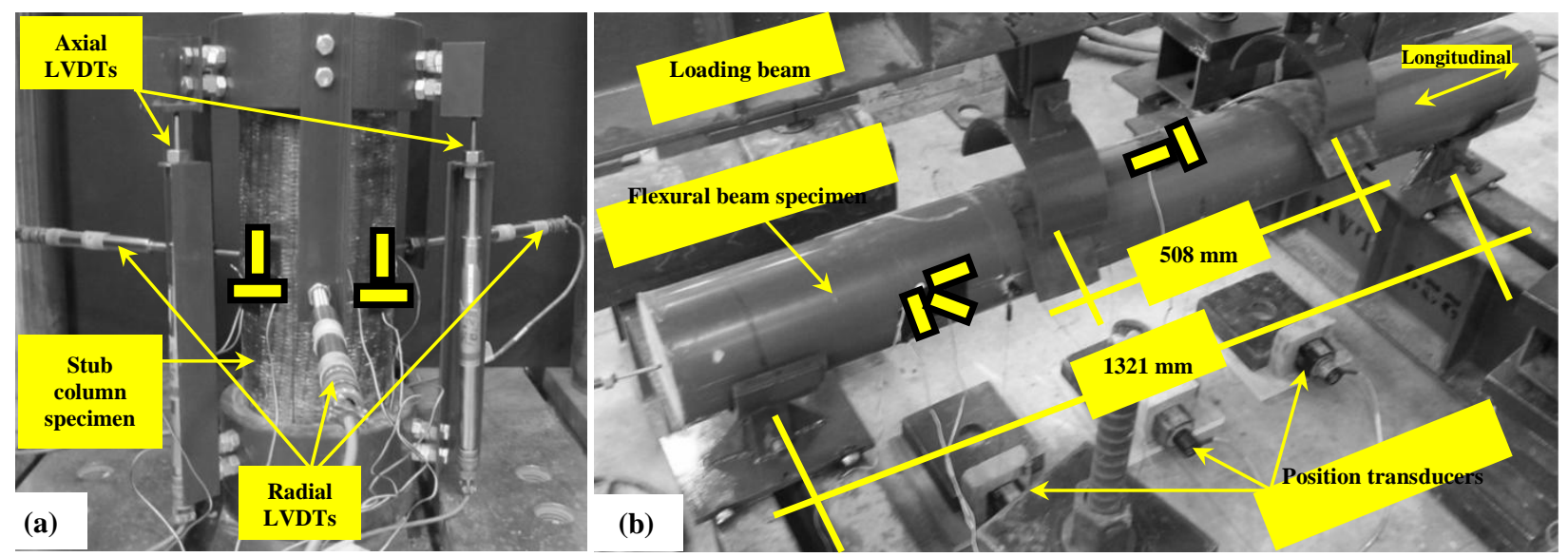

Fig. 3. Test setup: (a) stub column, and (b) flexural beam. ( $\square$ : strain gage)

Conversion: $1 \mathrm{~mm}=0.04 \mathrm{in}$. 


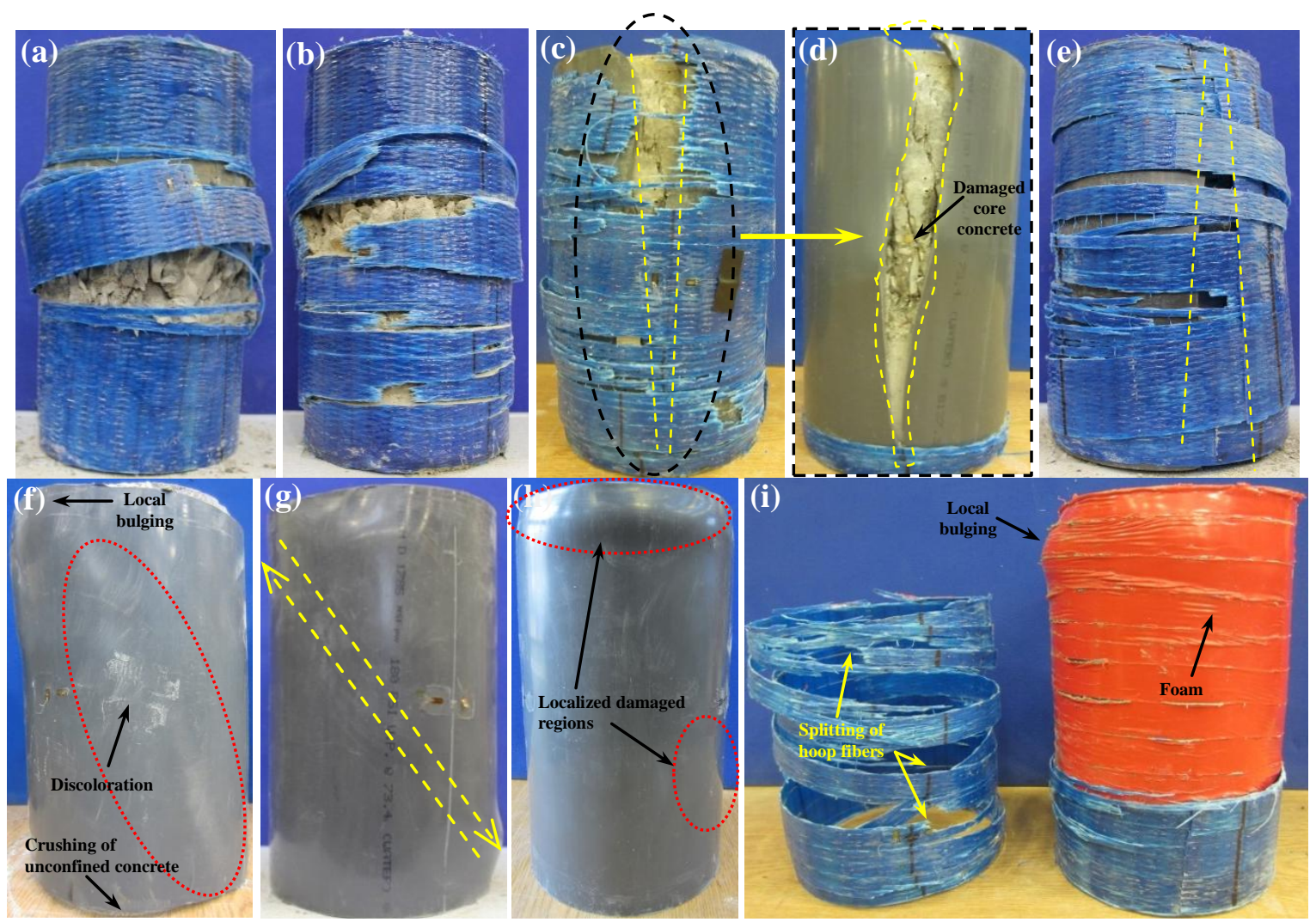

Fig. 4. Typical failure modes of stub columns: (a) FW-1G\#2, (b) FW-3G\#2, (c) CCFPT-G401G\#2, (d) CCFPT-G40-1G\#2 after FRP removal, (e) CCFPT-G40-3G\#3, (f) CFPT-G40-w gap\#1, (g) CFPT-G40\#1, (h) CFPT-G40\#2, and (i) CCFPT-G40-1G-foam\#3. 

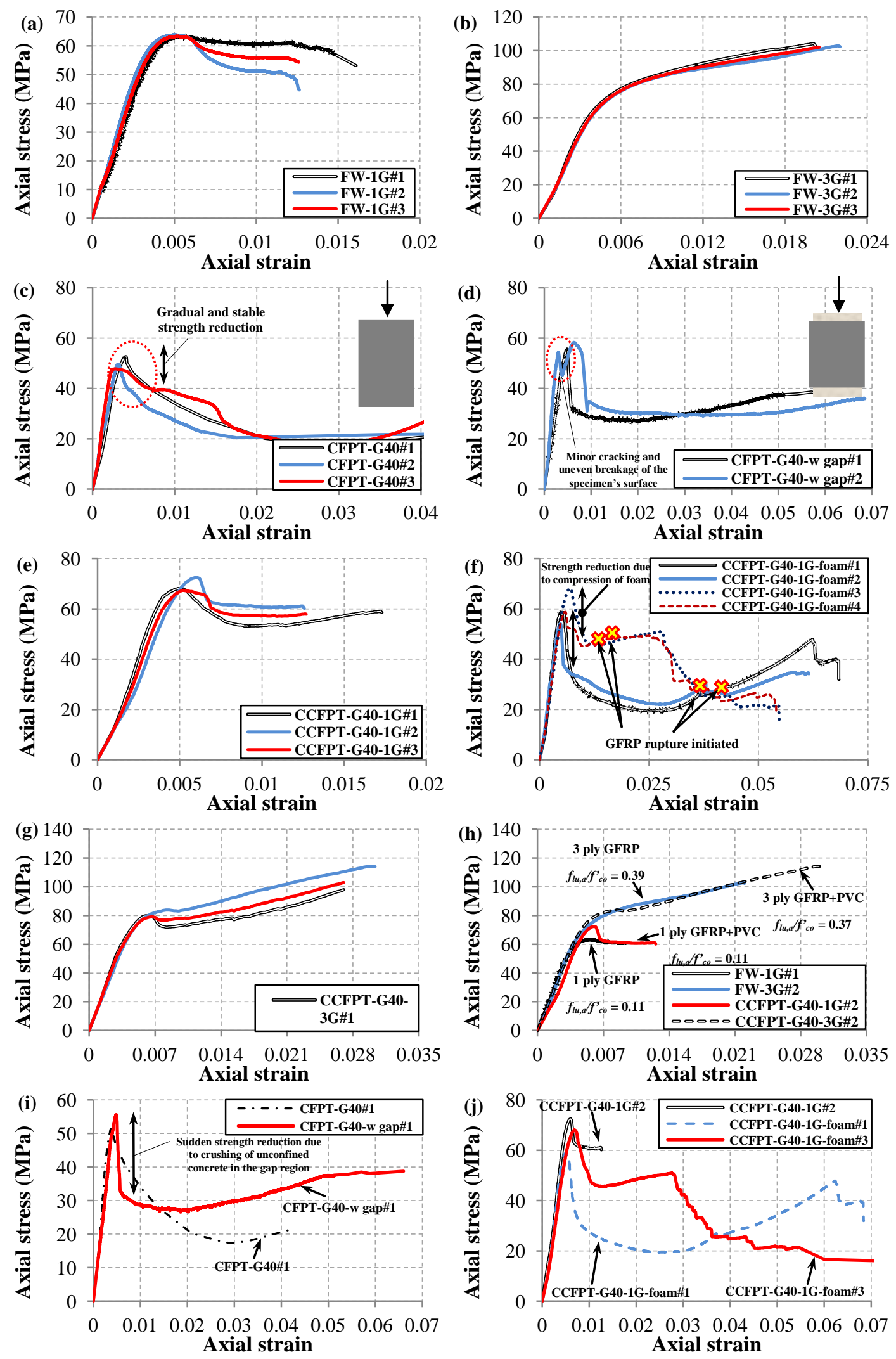

Fig. 5. Axial stress-strain curves of stub specimens: (a) FW-1G, (b) FW-3G, (c) CFPT-G40, (d) CFPT-G40-w gap, (e) CCFPT-G40-1G, (f) CCFPT-G40-1G-foam, (g) CCFPT-G40-3G, (h) FW versus CCFPT, (i) CFPT for gap effect, and (j) CCFPT for foam effect. 


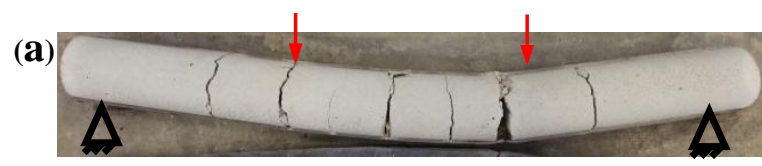

(b)

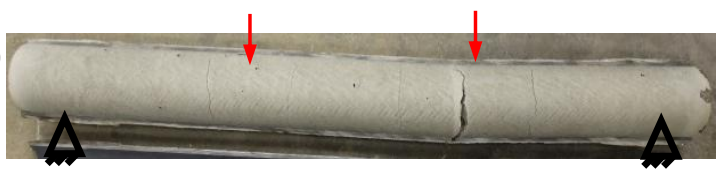

(c)

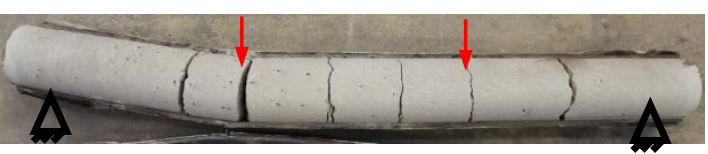

(d)

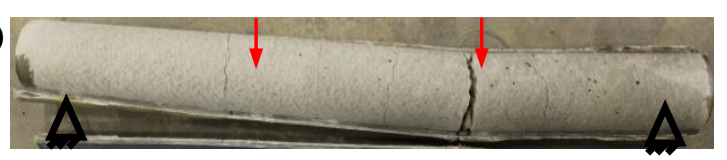

(e)

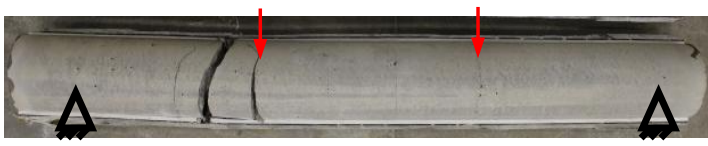

Fig. 6. Core concrete conditions of CFPT and CCFPT beam specimens after test: (a) CFPT-1, (b) CCFPT-1, (c) CCFPT-2, (d) CCFPT-3, and (e) CCFPT-4. 

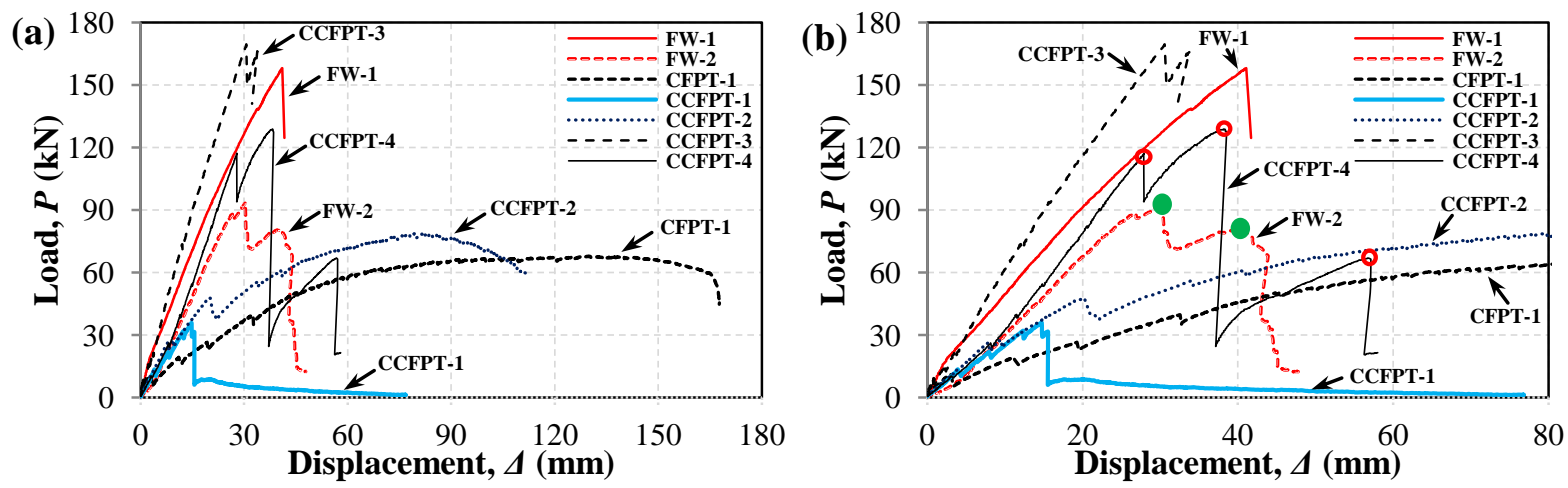

Fig. 7. Load-deflection curves of flexural beams

Conversion: $1 \mathrm{kN}=225 \mathrm{lbf} ; 1 \mathrm{~mm}=0.04 \mathrm{in}$. 
Table 1 Summary of stub column specimens test results

\begin{tabular}{|c|c|c|c|c|c|c|c|c|c|c|c|}
\hline $\begin{array}{l}\text { Confinement } \\
\text { type }\end{array}$ & Confinement detail & Specimen & $f_{l u} / f_{c o}^{\prime}$ & $f_{l u, a} / f_{c o}^{\prime}$ & $\begin{array}{c}f_{c c}^{\prime} \\
(\mathrm{MPa})\end{array}$ & $\begin{array}{c}f_{c u}^{\prime} \\
(\mathrm{MPa})\end{array}$ & $\begin{array}{c}\varepsilon_{c u} \\
(\%)\end{array}$ & $\begin{array}{c}\varepsilon_{h, r u p} \\
(\%)\end{array}$ & $f_{c d}^{\prime} / f_{c o}^{\prime}$ & $\varepsilon_{c u} / \varepsilon_{c o}$ & $k_{\varepsilon}$ \\
\hline \multirow{6}{*}{ 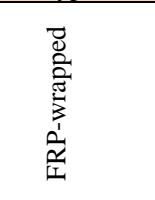 } & \multirow{3}{*}{1 ply GFRP } & FW-1G\#1 & 0.14 & 0.11 & 63.1 & 53.1 & 1.61 & 1.41 & 1.26 & 6.49 & \multirow{3}{*}{0.71} \\
\hline & & FW-1G\#2 & 0.14 & 0.10 & 63.8 & 44.7 & 1.26 & 1.29 & 1.28 & 5.08 & \\
\hline & & FW-1G\#3 & 0.14 & 0.10 & 63.3 & 54.3 & 1.26 & 1.25 & 1.27 & 5.08 & \\
\hline & \multirow{3}{*}{3 ply GFRP } & FW-3G\#1 & 0.43 & 0.35 & 104.2 & & 2.03 & 1.52 & 2.08 & 8.18 & \multirow{3}{*}{0.85} \\
\hline & & FW-3G\#2 & 0.43 & 0.39 & 102.3 & & 2.20 & 1.68 & 2.05 & 8.87 & \\
\hline & & FW-3G\#3 & 0.43 & 0.35 & 102.1 & & 2.05 & 1.52 & 2.04 & 8.26 & \\
\hline \multirow{5}{*}{ 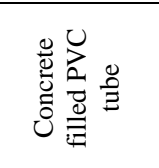 } & \multirow{3}{*}{ Sch. 40 PVC } & CFPT-G40\#1 & 0.08 & & 52.6 & 42.0 & 0.60 & & 1.05 & 2.42 & \\
\hline & & CFPT-G40\#2 & 0.08 & & 49.5 & 39.6 & 0.44 & & 0.99 & 1.81 & \\
\hline & & CFPT-G40\#3 & 0.08 & & 47.8 & 38.2 & 1.01 & & 0.96 & 4.07 & \\
\hline & \multirow{2}{*}{$\begin{array}{l}\text { Sch. } 40 \text { PVC with } 12 \mathrm{~mm} . \\
\text { gaps at both ends }\end{array}$} & CFPT-G40-w gap\#1 & 0.08 & & 55.5 & 44.4 & 0.50 & & 1.11 & 2.01 & \\
\hline & & CFPT-G40-w gap\#2 & 0.08 & & 58.2 & 46.6 & 0.81 & & 1.16 & 3.26 & \\
\hline \multirow{10}{*}{ 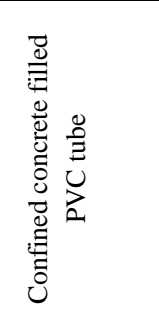 } & \multirow{3}{*}{ Sch. 40 PVC+1 ply GFRP } & CCFPT-G40-1G\#1 & 0.13 & 0.12 & 68.0 & 58.5 & 1.73 & 1.73 & 1.36 & 6.97 & \multirow{3}{*}{0.88} \\
\hline & & CCFPT-G40-1G\#2 & 0.13 & 0.11 & 72.4 & 60.2 & 1.26 & 1.58 & 1.45 & 5.08 & \\
\hline & & CCFPT-G40-1G\#3 & 0.13 & 0.11 & 67.4 & 57.8 & 1.27 & 1.59 & 1.35 & 5.12 & \\
\hline & \multirow{4}{*}{$\begin{array}{c}\text { Sch. } 40 \text { PVC+1 ply GFRP } \\
\text { with foam between PVC } \\
\text { tube and FRP wrap }\end{array}$} & CCFPT-G40-1G-foam\#1 & 0.13 & 0.13 & 58.7 & 47.0 & 0.62 & 1.84 & 1.17 & 2.50 & \multirow{4}{*}{0.97} \\
\hline & & CCFPT-G40-1G-foam\#2 & 0.13 & 0.13 & 54.0 & 43.2 & 0.53 & 1.80 & 1.08 & 2.14 & \\
\hline & & CCFPT-G40-1G-foam\#3 & 0.13 & 0.12 & 68.0 & 54.4 & 0.89 & 1.77 & 1.36 & 3.59 & \\
\hline & & CCFPT-G40-1G-foam\#4 & 0.13 & 0.12 & 58.8 & 47.0 & 0.90 & 1.78 & 1.18 & 3.63 & \\
\hline & \multirow{3}{*}{ Sch. 40 PVC +3 ply GFRP } & CCFPT-G40-3G\#1 & 0.39 & 0.35 & 97.9 & & 2.70 & 1.68 & 1.96 & 10.88 & \multirow{3}{*}{0.92} \\
\hline & & CCFPT-G40-3G\#2 & 0.39 & 0.37 & 114.3 & & 3.03 & 1.77 & 2.29 & 12.21 & \\
\hline & & CCFPT-G40-3G\#3 & 0.39 & 0.35 & 103.0 & & 2.71 & 1.67 & 2.06 & 10.92 & \\
\hline
\end{tabular}

Table 2 Summary of flexural beam specimens test results

\begin{tabular}{|c|c|c|c|c|c|c|c|c|c|c|}
\hline \multirow{2}{*}{$\begin{array}{l}\text { Confinement } \\
\text { type }\end{array}$} & \multirow[t]{2}{*}{ Specimen } & \multicolumn{2}{|c|}{$\begin{array}{l}\text { FRP fibers } \\
\text { orientation }\end{array}$} & \multirow[t]{2}{*}{$\begin{array}{l}\text { Stacking } \\
\text { sequence }\end{array}$} & \multirow[t]{2}{*}{ Foam } & \multirow[t]{2}{*}{$\begin{array}{l}P_{\text {peak }} \\
(\mathrm{kN})\end{array}$} & \multirow{2}{*}{$\begin{array}{c}M_{\text {peak }} \\
\text { (kN.m) }\end{array}$} & \multirow[t]{2}{*}{$\begin{array}{l}\Delta_{\text {peak }} \\
(\mathrm{mm})\end{array}$} & \multirow[t]{2}{*}{$\begin{array}{c}P_{u l t} \\
(\mathrm{kN})\end{array}$} & \multirow[t]{2}{*}{$\begin{array}{c}\Delta_{u l t} \\
(\mathrm{~mm})\end{array}$} \\
\hline & & Longitudinal & Hoop & & & & & & & \\
\hline \multirow[b]{2}{*}{$\begin{array}{c}\text { FRP- } \\
\text { wrapped }\end{array}$} & FW-1 & 2 & 3 & 2 long./3 hoop & - & 158.1 & 32.1 & 41.1 & & \\
\hline & FW-2 & 2 & 3 & $\begin{array}{l}1 \text { long./ foam/ } 1 \\
\text { long./ } 3 \text { hoop }\end{array}$ & Between long. FRP & 93.6 & 19.0 & 30.3 & 74.9 & 31.0 \\
\hline $\begin{array}{c}\text { Conctrete } \\
\text { filled PVC } \\
\text { tube }\end{array}$ & CFPT-1 & - & - & 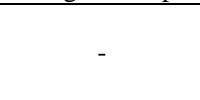 & - & 67.9 & 13.8 & 129.6 & 54.3 & 166.8 \\
\hline \multirow{4}{*}{$\begin{array}{l}\text { Confined } \\
\text { concrete } \\
\text { filled PVC } \\
\text { tube }\end{array}$} & CCFPT-1 & - & 3 & 3 hoop & - & 35.9 & 7.3 & 14.8 & & \\
\hline & CCFPT-2 & - & 3 & Foam/ 3 hoop & $\begin{array}{c}\text { Between PVC and hoop } \\
\text { FRP }\end{array}$ & 78.6 & 16.0 & 79.3 & 62.9 & 111.7 \\
\hline & CCFPT-3 & 2 & 3 & 2 long./ 3 hoop & - & 169.6 & 34.5 & 30.6 & & \\
\hline & CCFPT-4 & 2 & 3 & $\begin{array}{c}\text { Foam/ } 2 \text { long./ } 3 \\
\text { hoop }\end{array}$ & $\begin{array}{c}\text { Between PVC and long. } \\
\text { FRP }\end{array}$ & 128.7 & 26.2 & 58.0 & & \\
\hline
\end{tabular}

